\title{
Opioids inhibit visceral afferent activation of catecholamine neurons in the solitary tract nucleus
}

\author{
Ran Ji Cui, Ph.D. ${ }^{1}$, Brandon L. Roberts, B.Sc. ${ }^{1}$, Huan Zhao, Ph.D. ${ }^{1}$, Michael C. Andresen, \\ Ph.D. ${ }^{2}$, and Suzanne M. Appleyard, Ph.D. ${ }^{1,{ }^{*}}$ \\ ${ }^{1}$ Department of Veterinary Comparative Anatomy, Physiology and Pharmacology, Washington \\ State University, Pullman, WA 99164 \\ ${ }^{2}$ Department of Physiology and Pharmacology, Oregon Health \& Science University Portland, \\ Oregon USA 97239-3098
}

\section{Abstract}

Brainstem A2/C2 catecholamine (CA) neurons within the solitary tract nucleus (NTS) influence many homeostatic functions, including food intake, stress, respiratory and cardiovascular reflexes. They also play a role in both opioid reward and withdrawal. Injections of opioids into the NTS modulate many autonomic functions influenced by catecholamine neurons including food intake and cardiac function. We recently showed that NTS-CA neurons are directly activated by incoming visceral afferent inputs. Here we determined whether opioid agonists modulate afferent activation of NTS-CA neurons using transgenic mice with EGFP expressed under the control of the tyrosine hydroxylase promoter (TH-EGFP) to identify catecholamine neurons. The opioid agonist Met-enkephalin (Met-Enk) significantly attenuated solitary tract evoked EPSCs (STEPSCs) in NTS TH-EGFP neurons by $80 \%$, an effect reversed by wash or the mu opioid receptor specific antagonist, CTOP. Met-Enk had a significantly greater effect to inhibit afferent inputs onto TH-EGFP positive neurons than EGFP negative neurons, which were only inhibited by $50 \%$. The mu agonist, DAMGO, also inhibited the ST-EPSC in TH-EGFP neurons in a dose-dependent manner. In contrast, neither the delta agonist DPDPE, nor the kappa agonist, U69,593, consistently inhibited the ST-EPSC amplitude. Met-Enk and DAMGO increased the paired pulse ratio, decreased the frequency, but not amplitude, of mini-EPSCs and had no effect on holding current, input resistance or current-voltage relationships in TH-EGFP neurons, suggesting a presynaptic mechanism of action on afferent terminals. Met-Enk significantly reduced both the basal firing rate of NTS TH-EGFP neurons and the ability of afferent stimulation to evoke an action potential. These results suggest that opioids inhibit NTS-CA neurons by reducing an excitatory afferent drive onto these neurons through presynaptic inhibition of glutamate release and elucidate one

(C) 2012 Published by Elsevier Ltd on behalf of IBRO.

*To whom correspondence should be sent: Suzanne Appleyard, Department of VCAPP, Program in Neuroscience, Washington State University, 100 Dairy Road, Pullman, WA 99164, Tel: (509) 335-7784, Fax: (509) 335-4650, appleyas@ vetmed.wsu.edu. Publisher's Disclaimer: This is a PDF file of an unedited manuscript that has been accepted for publication. As a service to our customers we are providing this early version of the manuscript. The manuscript will undergo copyediting, typesetting, and review of the resulting proof before it is published in its final citable form. Please note that during the production process errors may be discovered which could affect the content, and all legal disclaimers that apply to the journal pertain.

Disclosure/Conflicts of interest: All of the authors have no conflicts of interest to declare. 
potential mechanism by which opioids could control autonomic functions and modulate reward and opioid withdrawal symptoms at the level of the NTS.

\section{Keywords}

Opioid; vagus; afferents; catecholamine; synaptic transmission; NTS

\section{1}

The solitary tract nucleus (NTS) broadly impacts homeostatic regulation as it is the primary site through which visceral afferent information concerning cardiovascular, respiratory and gastrointestinal systems enters the brain (Andresen \& Kunze, 1994; Saper, 2002). The $\mathrm{A}_{2} / \mathrm{C}_{2}$ group of catecholamine (CA) neurons lie within the dorsal vagal complex (DVC) and are ideally situated to co-ordinate afferent signaling to multiple brain regions through their extensive projections, including to the hypothalamus, amygdala, nucleus accumbens and other brainstem nuclei (Balcita-Pedicino \& Rinaman, 2007; Cunningham \& Sawchenko, 1988; Jia et al, 1997; Reyes \& Van Bockstaele, 2006; Rogers et al, 2003; Rukhadze \& Kubin, 2007; Sawchenko \& Pfeiffer, 1988; Sawchenko \& Swanson, 1981; Suzuki et al, 1997; Wang et al, 1992; Petrov et al, 1993; Riche et al, 1990; Travagli et al, 2006; Ueta et al, 2000; Wang et al, 1992). Release of norepinephrine and epinephrine at these target nuclei widely affects behaviors, including stress, anxiety, reward, food intake and cardiovascular function (Cole \& Sawchenko, 2002; Leibowitz et al, 1988; Smith \& Aston-Jones, 2008) and $\mathrm{A}_{2} / \mathrm{C}_{2}$ catecholamine neurons have been implicated in the regulation of these functions (Itoh \& Bunag, 1993; Kubo et al, 1990; Rinaman, 2011; Simon et al, 1985).

Opioids modulate many functions influenced by afferent inputs and CA neurons in the NTS. Injections of opioid agonists into the NTS increase food intake (Kotz et al, 1997) and decrease the baroreceptor reflex (Gordon, 1990; Hassen and Feuerstein, 1987), while antagonists have the converse effects (Giraudo et al, 1998; Glass et al, 2002; Kim et al, 2009; Kotz et al, 2000; Van Giersbergen et al, 1989; Xu et al, 1992). NTS-CA neurons are also proposed to be important for the rewarding aspects of opioids as re-expression of dopamine beta-hydroxylase, an enzyme critical for catecholamine synthesis in NTS neurons restores morphine-induced conditioned place preference (Olson et al, 2006). These neurons also undergo adaptive responses following chronic exposure to opioids (Van Bockstaele et al, 2001) and gene transcription is activated following opioid withdrawal (Benavides et al, 2005; Laorden et al, 2002) concomitant with an activation of both aversive (Delfs et al, 2000) and stress responses (Fuertes et al, 2000a; Fuertes et al, 2000b; Laorden et al, 2000; Navarro-Zaragoza et al, 2010; Navarro-Zaragoza et al, 2011; Nunez et al, 2008; Nunez et al, 2010). Furthermore, brainstem $C A$ neuron projections, including the $A_{2} / C_{2}$ group, making up the ventral noradrenergic bundle appear to be critical for both the aversive effects following acute morphine withdrawal (Delfs et al, 2000) and the stress-induced reactivation of morphine conditioned place preference following abstinence (Delfs et al, 2000; Wang et al, 2001). Norepinephrine release in the extended amygdala is hypothesized to mediate many of the aversive aspects of opioid withdrawal as well as stress-induced relapse of drug- 
seeking for opioids and other drugs of abuse including cocaine, ethanol and nicotine (Smith $\&$ Aston-Jones, 2008).

NTS-CA neurons are strongly and directly activated by incoming visceral afferents through the release of the excitatory transmitter glutamate (Appleyard et al, 2007; Cui et al, 2011). However, the propagation of afferent information to downstream targets by NTS-CA neurons depends on the translation of afferent glutamate release into postsynaptic action potential (AP) activity. This can be influenced by multiple factors, including presynaptic modulation of glutamate release (Appleyard et al, 2007; Bailey et al, 2006; Cui et al, 2011; Peters et al, 2008) and expression of different types of ion channels (Appleyard et al, 2007; Bailey et al, 2007). Opioids inhibit the release of norepinephrine acutely in NTS slices (AlKhrasani et al, 2003; Arakawa et al, 1991). However, the cellular mechanisms by which opioids regulate glutamate release and influence the activity of this critical group of CA neurons are not known. The goals of this study were to determine whether opioids modulate afferent activation of NTS-CA neurons and the cellular mechanisms involved.

\subsection{Experimental Procedures}

\subsubsection{NTS slices}

Hindbrains of male TH-EGFP mice (6-16 weeks old) were prepared as previously described (Appleyard et al, 2007). All animal procedures were conducted with the approval of the Animal Care and Use Committees at either OHSU or WSU and in accordance with the U.S. Public Health Service Policy on Humane Care and Use of Laboratory Animals (PHS Policy) and the National Institutes of Health Guide for the Care and Use of Laboratory Animals (NIH Guide). The hindbrain was removed and placed for one minute in cold $\left(0-4^{\circ} \mathrm{C}\right)$ artificial cerebral spinal fluid composed of $(\mathrm{mM}): 125 \mathrm{NaCl}, 3 \mathrm{KCl}, 1.2 \mathrm{KH}_{2} \mathrm{PO}_{4}, 1.2$ $\mathrm{MgSO}_{4}, 25 \mathrm{NaHCO}_{3}, 10$ dextrose, $2 \mathrm{CaCl}_{2}$, and bubbled with $95 \% \mathrm{O}_{2} / 5 \% \mathrm{CO}_{2}$. The medulla was trimmed to a $2 \mathrm{~cm}$ block (rostral-caudal) centered on the obex. A wedge of tissue was removed from the ventral surface to align the ST with the cutting plane when mounted in a vibrating microtome (Leica VT-1000S). Slices ( $250 \mu \mathrm{m}$ thick) cut with a sapphire knife (Delaware Diamond Knives) contained the ST in the same plane as the NTS (but more dorsal than the dorsal motor nucleus of the vagus (DMNV). Slices were submerged in a perfusion chamber and all recordings performed at $31-35^{\circ} \mathrm{C}$ and $\mathrm{pH}$ 7.4. The osmolarity was adjusted to 301-305 mOsm using dextrose. Neurons were visualized using an upright microscope (Olympus BX51 or Zeiss Axioskop). Recording electrodes were filled with a solution (mM): $10 \mathrm{NaCl}, 130 \mathrm{~K}$ gluconate, 11 EGTA, $1 \mathrm{CaCl}_{2}, 2 \mathrm{MgCl}_{2}, 10$ HEPES, 2 NaATP, 0.2 NaGTP; pH 7.3; 297-301 mOsm. Neurons were recorded from NTS within 200 $\mu \mathrm{m}$ rostral or caudal from obex and medial to the ST - medial NTS (mNTS). Patch electrodes, 3-5 M $\Omega$, were guided to neurons using differential interference contrast (DIC) optics illuminated with infrared light (Olympus B51 or Zeiss Axioskop). Voltage clamp recordings were made with an Axopatch 700B and pClamp 9 or 10 software (Axon Instruments). Only neurons with holding currents not exceeding $100 \mathrm{pA}$ at $\mathrm{V}_{\mathrm{H}}=-60 \mathrm{mV}$ for the 15 minute control period (input resistance $>150 \mathrm{M} \Omega$ ) were studied further. Synaptic currents were evoked with an ultrafine concentric bipolar stimulating electrode (50 $\mu \mathrm{m} \mathrm{ID,}$ F. Haer) placed on the ST 1-3 mm from the recording electrode. Electrical stimuli were 
delivered from an isolated programmable stimulator (Master-8, AMPI) triggered to deliver a burst of five stimuli $(20-50 \mathrm{~Hz}$ ). Highly consistent ST latencies (SD latency or jitter <200 $\mu$ s) identified neurons that are second order to ST were studied (Doyle \& Andresen, 2001). Most analyses examined the first EPSC of each train and averaged responses across multiple trials (>20) within each neuron unless otherwise noted. All drugs were obtained from Tocris Cookson (Ballwin, MO) or Sigma (St Louis, MO). As previously characterized, TH-EGFP neurons often receive multiple monosynaptic afferent inputs, as well as polysynaptic inputs, resulting in a compound EPSC (Appleyard et al, 2007) and all drug effects are reported on the compound EPSC amplitudes. Failure to detect a synaptic event at the expected latency for a given ST-EPSC was considered a synaptic failure and failure rate was calculated as the number of missed events divided by the number $(>20)$ of successive ST shock trials and expressed as the percent failing. The failure rate reported is for the compound ST-EPSC, acknowledging that this may underestimate each individual input's failure rate. However, all neurons studied had at least one direct input that must fail for there to be an overall increase in failure rate.

\subsubsection{Statistical Analysis}

All data are presented as averages \pm SEM. Statistical comparisons were made using unpaired Student's $t$-test or one way ANOVA, and Fisher's PLSD post hoc analysis where appropriate (see individual results; Statview 4.57, Abacus Concepts). The KolmogorovSmirnov test (KS-test) determined the significance of the drug effect for individual neurons when analyzing the mEPSC data (Mini analysis, Synaptosoft). $\mathrm{p}<0.05$ was considered a statistically significant difference.

\subsection{Results}

\subsubsection{Opioid inhibition of ST-stimulated EPSCs}

Horizontal brainstem slices were cut to preserve a lengthy segment of the ST in the same plane as the cell bodies of NTS (Figure 1A). This configuration allows the stimulating electrode to be placed on the visible ST at a sufficient distance from the recording area to minimize focal activation of local interneurons and interconnecting fibers (Bailey et al., 2008). Brief shocks (100 $\mu$ s duration) to the ST evoked excitatory postsynaptic currents (STEPSCs) in the TH-EGFP neurons. As we have described previously, ST-EPSCs in THEGFP neurons were mediated by non-NMDA ionotropic glutamate receptors and had nearly invariant latencies, few failures, and substantial frequency-dependent amplitude depression marking them as second order neurons (Appleyard et al, 2007). Bath application of the endogenous opioid agonist $10 \mu \mathrm{M}$ Met-Enkephalin (Met-Enk), which activates both the mu and delta opioid receptors (Bodnar, 2010), inhibited the amplitude of the initial ST-EPSC of the burst (Control amplitude $=415 \pm 67 \mathrm{pA}$, Met-Enk $=70 \pm 19 \mathrm{pA}, \mathrm{n}=8$, Figure 1B, C). The opioid receptor mediated inhibition had a fast onset and was sustained during drug perfusion but was quickly reversed following a 10 minute wash (Wash $=388 \pm 77 \mathrm{pA}, \mathrm{n}=8$, Figure 1B,C). 


\subsubsection{Met-Enkephalin increases both the paired pulse ratio and the failure rate of ST-EPSC in TH-EGFP neurons}

Met-Enk (10uM) significantly increased the paired pulse ratio of the ST-EPSCs in NTS-CA neurons (Figure 1D, $n=7$ ), thus suppressing frequency dependent depression. Met-Enk also caused failures, where ST stimulation did not evoke an EPSC (Figure 1E, n=7).

\subsubsection{The mu receptor mediates the opioid inhibition of ST-EPSC amplitude}

To establish which receptor(s) contribute to the opioid inhibition of the ST-EPSC amplitude, we tested the effects of selective opioid receptor agonists and antagonists. Application of the $\mathrm{mu}$ opioid receptor selective agonist DAMGO $(100 \mathrm{nM})$ significantly inhibited the EPSC amplitude $($ Control amplitude $=-381 \pm 131 \mathrm{pA}, 100 \mathrm{nM}$ DAMGO $=-127 \pm 54 \mathrm{pA}, \mathrm{n}=5$, Figure 2A,B). The DAMGO effect was reversed when the non-specific opioid antagonist naloxone $(10 \mu \mathrm{M})$ was co-applied with DAMGO (DAMGO + Naloxone $=-327 \pm 137 \mathrm{pA}, \mathrm{n}$ $=5$, Figure $2 \mathrm{~A}, \mathrm{~B})$. DAMGO $(100 \mathrm{nM})$ also significantly increased the paired pulse ratio of the ST-EPSCs in NTS-CA neurons, an effect reversed by co-application of naloxone (10 $\mu \mathrm{M}, \mathrm{n}=5$ ).

The effects of DAMGO were concentration dependent (Figure 2C), with an $\mathrm{EC}_{50}$ for the DAMGO mediated inhibition of ST-EPSCs in TH-EGFP neurons of approximately $15 \mathrm{nM}$ (Figure 2B). DAMGO had no effect on the input resistance (Control DAMGO $=573 \pm 88$ $\mathrm{m} \Omega ; 100 \mathrm{nM}$ DAMGO $554 \pm 92 \mathrm{~m} \Omega$; DAMGO + Naloxone $523 \pm 99$ ) or holding current of the TH-EGFP neurons.

The Met-Enk inhibition of the ST-EPSC amplitude was blocked by the mu opioid selective antagonist CTOP (D-Phe-Cys-Tyr-D-Trp-Orn-Thr-Pen-Thr- $\mathrm{NH}_{2}, 1 \mathrm{uM}$ ) (Figure 2C; Control Amplitude $=-280 \pm 30$, CTOP only amplitude $=-250 \pm 25 \mathrm{pA} ;$ CTOP + Met-Enk $=-211 \pm$ $24 \mathrm{pA}, \mathrm{n}=8$, CTOP vs. CTOP + Met-Enk). Neither the delta opioid selective agonist, DPDPE (1 uM), or the kappa opioid selective agonist, U69,593 (1 uM) had a significant effect on the amplitude of the ST-EPSCs in NTS-CA neurons (Figure 2C; Control DPDPE Amplitude $=-245 \pm 62$, DPDPE amplitude $=-214 \pm 55 \mathrm{pA}, \mathrm{n}=5$, Control vs. DPDPE $\mathrm{p}>$ 0.05; Student's t test; Control U50,488 Amplitude $=-246 \pm 37$, U50,488 amplitude $=-230$ \pm 34 pA, n=8 Control vs. U50,488 p > 0.05; Student's t test; Figure 2C).

\subsubsection{The opioid effect is larger in TH-EGFP positive neurons than EGFP negative neurons}

We next compared responses to Met-Enk on the ST-EPSC amplitudes of TH positive and neighboring EGFP negative second order NTS neurons. The level of inhibition by Met-Enk of ST-EPSC amplitude in non-EGFP neurons was significantly less than in TH-EGFP neurons (Figure 3; $p<0.005$, non-paired Students t test). On average Met-Enk inhibited the ST-EPSC amplitude in EGFP negative neurons from $-232.1 \pm 26.9 \mathrm{pA}$ to $-119.7 \pm 10.8 \mathrm{pA}$ $(\mathrm{n}=8)$. Met-Enk had no effect on the input resistance of the TH-EGFP negative neurons $($ Control $=503.4 \pm 32.3$, Met-Enk $=538 \pm 41 ;$ wash $=519 \pm 26 \mathrm{M} \Omega)$.

\subsubsection{Presynaptic actions of Met-Enkephalin on glutamate inputs onto TH-EGFP neurons}

To better focus on possible presynaptic mechanisms, we next looked at miniature EPSCs (mEPSCs). These experiments were carried out in the presence of TTX to block action 
potential evoked activity so that changes in frequency indicate changes in vesicle release probability. The holding potential was held at $-60 \mathrm{mV}$, the approximate reversal potential for chloride in our recording conditions and gabazine $(2 \mu \mathrm{M})$ was included in some experiments to eliminate mIPSCs. Met-Enk rapidly decreased the frequency of mEPSCs in all neurons tested ( $\mathrm{n}=7, \mathrm{p}<0.01, \mathrm{~K}-\mathrm{S}$ test) from an average of $3.62 \pm 0.67 \mathrm{~Hz}$ in control to $1.44 \pm 0.28$ $\mathrm{Hz}$ in Met-Enk (Figure 4A, B, D). This effect was readily reversed by a 10 minute wash to $3.39 \pm 0.52 \mathrm{~Hz}$ (Figure 4A, B, D). In contrast, Met-Enk had no consistent effect on mEPSC amplitude (Figure 4C). DAMGO also significantly decreased the frequency of mEPSCs in 5 out of 6 neurons tested ( $<<0.01$, KS test) from $3.47 \pm 0.93 \mathrm{~Hz}$ in control to $2.50 \pm 0.92 \mathrm{~Hz}$ in $300 \mathrm{nM}$ DAMGO (Figure 4D). This effect was reversed by the opioid antagonist naloxone to $4.01 \pm 1.12 \mathrm{~Hz}$ (Figure 4D). DAMGO had no consistent effect on mEPSC amplitude distributions $(\mathrm{P}>0.05$, KS test).

To examine the post-synaptic effects of opioids in more detail we also tested the effect of opioids on current-voltage relationships (Figure 5). Met-Enk did not alter either the peak or sustained outward currents following an activation protocol (where the neuron was first stepped to $-120 \mathrm{mV}$ to remove voltage-dependent inactivation of channels).

\subsubsection{Opioids inhibit ST-evoked action potentials in TH-EGFP neurons}

To test whether opioids also inhibit the translation of ST afferent activity into post-synaptic action potentials (APs) in TH-EGFP neurons, we recorded membrane potential and APs under current clamp. Met-Enk inhibited the spontaneous basal firing rate of TH-EGFP neurons (Figure 6A and $\mathrm{C}, \mathrm{n}=8)$. Met-Enk caused a small hyperpolarization $(2-4 \mathrm{mV}$ change) in 3/8 TH-EGFP neurons. Met-Enk also significantly reduced the translation of the ST afferent activations into successful APs, an effect partially reversed by wash (Figure 6B and $\mathrm{D}, \mathrm{n}=5)$.

\subsubsection{Discussion}

NTS-CA neurons coordinate homeostatic changes linked to behaviors that are especially pronounced in regulation of food intake, cardiovascular function, stress responses and motivation (Rinaman, 2011). NTS-CA neurons are also thought to be required for the rewarding effects of opioids (Olson et al, 2006), as well as the manifestation of some symptoms of opioid withdrawal (Smith \& Aston Jones, 2008; Van Bockstaele et al., 2001; Laorden et al., 2002). Here we report five key new findings. First, opioids act through mu opioid receptors (MOP-Rs) on ST afferents to inhibit sensory activation of NTS TH-EGFP neurons. Second, opioid actions were substantially larger in TH-EGFP neurons compared to neighboring non-TH second order neurons. Third, activation of MOP-Rs decreased the probability of glutamate release from afferent terminals suggesting the inhibition is presynaptic. Fourth, opioids increased the failure rate for evoked EPSCs, suggesting an additional potential mechanism of action to cause conduction block in the presynaptic terminal. Fifth, this opioid induced inhibition translated into a reduced ability of sensory afferents to initiate action potentials in NTS TH-EGFP neurons indicating highly opioidsensitive control of release of catecholamines at downstream projection sites and the subsequent coordination of homeostatic functions. 


\subsubsection{Opioids act presynaptically on mu opioid receptors to reduce glutamate release from afferent terminals}

Our finding that the MOP-R is the predominant opioid receptor that inhibits afferent inputs onto NTS TH-EGFP neurons is consistent with in vivo studies showing that mu agonists cause the largest inhibition of food intake compared to delta or kappa agonists when injected into the NTS (Kotz et al, 1997). The fact that we saw no effect of either delta or kappa agonists on afferent inputs onto identified TH-EGFP neurons suggests that other phenotypes of NTS neurons must mediate the effects of kappa agonists that have been reported in the NTS (Poole et al, 2007).

Our results also indicate a presynaptic mechanism of action of opioids to decrease the probability of glutamate release from afferent terminals, as we saw a change in the PPR and an inhibition of mEPSC frequency (but not amplitude). In addition, Met-Enk increased the failure rate of ST-EPSCs suggesting that opioid receptors also decrease the ability of the STevoked APs to invade and depolarize the presynaptic terminal as has been previously reported for vasopressin in the NTS (Bailey et al, 2006). In contrast, we found no evidence of any postsynaptic effects of opioids in NTS TH-EGFP neurons, suggesting that the postsynaptic actions of mu opioids observed previously in the NTS are not on CA neurons (Rhim et al., 1993; Poole et al., 2007). A pre-synaptic mechanism of action is consistent with the finding that MOP-Rs are expressed in vagal afferent terminals (Aicher et al, 2000; Nomura et al., 1996). The signal transduction mechanism involved remains to be established. MOP-Rs inhibit neurotransmitter release in other brain regions through activation of potassium channels (Vaughan et al., 1997; Manzoni \& Williams, 1999; Zhu \& Pan, 2005) and potassium channels have been shown to be important for opioid inhibition of evoked glutamate EPSCs in the NTS (Ohi et al., 2007). However, opioids have also been shown to inhibit calcium currents in nodose ganglia neurons, the cell bodies of the vagal afferents (Rusin \& Moises, 1998; Hamra et al., 1999), and opioids decreases glutamate release from sensory afferents in the spinal cord through inhibition of calcium channels (Heinke et al., 2011). Therefore, opioids could decrease glutamate release via multiple mechanisms; for example inhibition of calcium channels to decrease calcium entry and reduce the probability of glutamate release and activation of potassium channels to decrease action potential invasion and terminal depolarization, which would further decrease calcium entry and could also explain the release failures we observed.

\subsubsection{Opioid effects on NTS-CA neurons are large and widespread}

MOP-R agonists powerfully inhibited afferent inputs onto all TH-EGFP neurons examined. This potent, widespread effect is in contrast to other peptides, such as ghrelin (Cui et al, 2011) or cholecystokinin (Appleyard et al, 2007). Indeed, across all NTS neurons only $\mathrm{GABA}_{\mathrm{B}}$ receptors (Fawley et al, 2011) so completely and universally depresses glutamate release from ST afferents; compared to other GPCRs such as vasopressin (Bailey et al, 2006), oxytocin (Peters et al, 2008) or Angiotensin II (Barnes et al, 2003), which have much more limited actions. 
Met-Enk caused a substantially larger inhibition of ST inputs onto TH positive neurons than TH negative neurons, suggesting that, as a population, NTS-CA neurons receive afferent inputs that are particularly enriched in mu opioid receptors and / or their transduction mechanism(s). The average size of inhibition of the EGFP negative neurons is quantitatively similar to the inhibition reported by others for unidentified rat NTS neurons (Glatzer \& Smith, 2005; Poole et al, 2007; Rhim et al, 1993) and that we have previously reported for both POMC-EGFP and other mouse NTS neurons (Appleyard et al, 2005).

\subsubsection{Opioids decrease action potential generation in NTS-TH neurons}

Our results demonstrate that opioids potently inhibit the ability of the solitary tract, the main excitatory input onto NTS-TH neurons, to evoke action potentials in NTS TH-EGFP neurons. Met-Enk also decreases the basal firing rate of these neurons, without any evidence of a post-synaptic effect. Neuropeptides can dynamically adjust the firing frequency of neurons by altering spontaneous glutamate inputs (Lee et al., 2010; Sutton et al., 2006; Yang et al., 2011) and we have previously shown that the firing frequency of NTS TH neurons is dependent on the frequency of spontaneous glutamate inputs (Cui et al., 2011). Blocking AMPA receptors also hyperpolarizes a subpopulation of NTS TH neurons (Cui et al, 2011) suggesting that the small hyperpolarization induced by opioids in some NTS TH neurons could also be due to the decrease in glutamate inputs.

\subsubsection{Endogenous sources of opioids in the NTS}

There are several sources of endogenous opioids that could activate the mu receptor. POMC neurons, a potential source of beta-endorphin (Palkovits \& Eskay, 1987), enkephalinergic neurons (Cheng et al, 1996; Velley et al, 1991) and endomorphin neurons (Martin-Schild et al, 1999; Pierce \& Wessendorf, 2000) have all been reported in the NTS. Terminals of MetEnk positive neurons have been found in close proximity to the catecholamine neurons (Pickel et al, 1989). An endogenous opioid tone has been reported in the NTS in vivo (Kotz et al, 1997). We did not see any evidence of a basal tone, as naloxone did not affect the STEPSC amplitude on its own, suggesting we have lost the drive or pathway responsible for the basal release of opioids in the NTS in our slices.

\subsubsection{Physiological implications for opioid inhibition of afferent inputs onto NTS-CA neurons}

The potent inhibitory effect of opioids on the firing rate of NTS TH-EGFP neurons predicts that the activity of these neurons in vivo, and therefore the amount of catecholamine released at their projection sites, will be strongly influenced by both endogenous opioid tone as well as exogenously applied opioids, including clinically used opioids and some drugs of abuse. NTS-CA neurons make extensive projections to many nuclei throughout the brain, including the paraventricular and arcuate nuclei of the hypothalamus, the amygdala, nucleus accumbens and other medullary nuclei (Balcita-Pedicino \& Rinaman, 2007; Cunningham \& Sawchenko, 1988; Jia et al, 1997; Reyes \& Van Bockstaele, 2006; Rogers et al, 2003; Rukhadze \& Kubin, 2007; Sawchenko \& Pfeiffer, 1988; Sawchenko \& Swanson, 1981; Suzuki et al, 1997; Wang et al, 1992). As we found that all NTS TH-EGFP neurons are 
sensitive to opioids, our data suggests that opioids will inhibit afferent-driven catecholamine release in all these regions. Thus, our findings suggest a cellular mechanism that could underlie the in vivo effects of opioids acting in the NTS to broadly influence many behaviors, such as food intake, aversion/motivation, stress and cardiovascular function (Giraudo et al, 1998; Kim et al, 2009; Kotz et al, 1997; Kotz et al, 2000; Van Giersbergen et al, 1989; Xu et al, 1992).

The inhibitory action of opioids on NTS-CA neurons is similar to their inhibitory effect on other brainstem CA neurons, such as Locus Coeruleus (LC) CA neurons (Christie, 1991). However, the underlying mechanisms appear to be different, as opioids have large direct postsynaptic effects on LC neurons (Christie, 1991), while we identified a presynaptic mechanism of action to inhibit the excitation of NTS-CA neurons by decreasing incoming glutamatergic excitatory drive. Interestingly, opioid withdrawal induces a rebound increase in the firing rate of LC neurons (Cao et al, 2010; Kogan et al, 1992; Lane-Ladd et al, 1997). However, while gene transcription is activated in NTS-CA neurons during withdrawal (Benavides et al, 2005; Van Bockstaele et al, 2001), the effect of opioid withdrawal on the firing rate of NTS-CA neurons remains to be determined.

\subsection{1}

In conclusion, our data shows that opioids inhibit visceral afferent excitatory inputs onto NTS-CA neurons resulting in a decreased firing rate of these neurons. These results demonstrate a potential mechanism by which opioids could regulate afferent drive of catecholamine release, which would then influence many functions, including food intake, cardiovascular reflexes, stress and reward.

\section{Acknowledgments}

This work was supported by grants from the National Institutes of Health (DK083452 and HL41119). The content is solely the responsibility of the authors and does not necessarily represent the official views of the National Institute of Diabetes and Digestion and Kidney disease, the National Heart, Lung and Blood Institute or the National Institutes for Health.

\section{References}

Aicher SA, Goldberg A, Sharma S, Pickel VM. mu-opioid receptors are present in vagal afferents and their dendritic targets in the medial nucleus tractus solitarius. J Comp Neurol. 2000; 422:181-190. [PubMed: 10842226]

Al-Khrasani M, Elor G, Yusuf Abbas M, Ronai AZ. The effect of endomorphins on the release of 3Hnorepinephrine from rat nucleus tractus solitarii slices. Regul Pept. 2003; 111:97-101. [PubMed: 12609755]

Andresen MC, Kunze DL. Nucleus tractus solitarius--gateway to neural circulatory control. Annu Rev Physiol. 1994; 56:93-116. [PubMed: 7912060]

Appleyard SM, Bailey TW, Doyle MW, Jin YH, Smart JL, Low MJ, Andresen MC. Proopiomelanocortin neurons in nucleus tractus solitarius are activated by visceral afferents: regulation by cholecystokinin and opioids. J Neurosci. 2005; 25:3578-3585. [PubMed: 15814788]

Appleyard SM, Marks D, Kobayashi K, Okano H, Low MJ, Andresen MC. Visceral afferents directly activate catecholamine neurons in the solitary tract nucleus. J Neurosci. 2007; 27:13292-13302. [PubMed: 18045923] 
Arakawa K, De Jong W, Mulder AH, Versteeg DH. The electrically stimulated release of $[3 \mathrm{H}]$ noradrenaline from nucleus tractus solitarii slices in vitro is modulated via mu-opioid receptors. Eur J Pharmacol. 1991; 192:311-316. [PubMed: 1674475]

Bailey TW, Jin YH, Doyle MW, Smith SM, Andresen MC. Vasopressin inhibits glutamate release via two distinct modes in the brainstem. J Neurosci. 2006; 26:6131-6142. [PubMed: 16763021]

Bailey TW, Hermes SM, Whittier KL, Aicher SA, Andresen MC. A-type potassium channels differentially tune afferent pathways from rat solitary tract nucleus to caudal ventrolateral medulla or paraventricular hypothalamus. J Physiol. 2007; 582:613-628. [PubMed: 17510187]

Bailey TW, Appleyard SM, Jin YH, Andresen MC. Organization and properties of GABAergic neurons in solitary tract nucleus (NTS). J. Neurophysiol. 2008; 99:1712-1722. [PubMed: 18272881]

Balcita-Pedicino JJ, Rinaman L. Noradrenergic axon terminals contact gastric preautonomic neurons in the paraventricular nucleus of the hypothalamus in rats. J Comp Neurol. 2007; 501:608-618. [PubMed: 17278138]

Barnes KL, DeWeese DM, Andresen MC. Angiotensin potentiates excitatory sensory synaptic transmission to medial solitary tract nucleus neurons. Am J Physiol Regul Integr Comp Physiol. 2003; 284:R1340-R1353. [PubMed: 12531785]

Bello NT, Patinkin ZW, Moran TH. Opioidergic consequences of dietary-induced binge eating. Physiology \& behavior. 2011

Benavides M, Laorden ML, Milanes MV. Involvement of 3',5'-cyclic adenosine monophosphatedependent protein kinase in regulation of Fos expression and tyrosine hydroxylase levels during morphine withdrawal in the hypothalamic paraventricular nucleus and medulla oblongata catecholaminergic cell groups. J Neurochem. 2005; 92:246-254. [PubMed: 15663473]

Bodnar RJ. Endogenous opiates and behavior: 2009. Peptides. 2010; 31:2325-2359. [PubMed: 20875476]

Browning KN, Kalyuzhny AE, Travagli RA. Mu-opioid receptor trafficking on inhibitory synapses in the rat brainstem. J. Neurosci. 2004; 24:9344-9352.

Brunton PJ, Meddle SL, Ma S, Ochedalski T, Douglas AJ, Russell JA. Endogenous opioids and attenuated hypothalamic-pituitary-adrenal axis responses to immune challenge in pregnant rats. $\mathrm{J}$ Neurosci. 2005; 25:5117-5126. [PubMed: 15917452]

Cao JL, Vialou VF, Lobo MK, Robison AJ, Neve RL, Cooper DC, Nestler EJ, Han MH. Essential role of the cAMP-cAMP response-element binding protein pathway in opiate-induced homeostatic adaptations of locus coeruleus neurons. Proc Natl Acad Sci U S A. 2010; 107:17011-17016. [PubMed: 20837544]

Cheng PY, Liu-Chen LY, Chen C, Pickel VM. Immunolabeling of Mu opioid receptors in the rat nucleus of the solitary tract: extrasynaptic plasmalemmal localization and association with Leu5enkephalin. J Comp Neurol. 1996; 371:522-536. [PubMed: 8841907]

Christie MJ. Mechanisms of opioid actions on neurons of the locus coeruleus. Prog Brain Res. 1991; 88:197-205. [PubMed: 1667545]

Cole RL, Sawchenko PE. Neurotransmitter regulation of cellular activation and neuropeptide gene expression in the paraventricular nucleus of the hypothalamus. J Neurosci. 2002; 22:959-969. [PubMed: 11826124]

Cui RJ, Li X, Appleyard SM. Ghrelin inhibits visceral afferent activation of catecholamine neurons in the solitary tract nucleus. J Neurosci. 2011; 31:3484-3492. [PubMed: 21368060]

Cunningham ET Jr, Sawchenko PE. Anatomical specificity of noradrenergic inputs to the paraventricular and supraoptic nuclei of the rat hypothalamus. J Comp Neurol. 1988; 274:60-76. [PubMed: 2458397]

Delfs JM, Zhu Y, Druhan JP, Aston-Jones G. Noradrenaline in the ventral forebrain is critical for opiate withdrawal-induced aversion. Nature. 2000; 403:430-434. [PubMed: 10667795]

Doyle MW, Andresen MC. Reliability of monosynaptic sensory transmission in brain stem neurons in vitro. J. Neurophysiol. 2001; 85:2213-2223. [PubMed: 11353036]

Ericsson A, Kovacs KJ, Sawchenko PE. A functional anatomical analysis of central pathways subserving the effects of interleukin-1 on stress-related neuroendocrine neurons. J Neurosci. 1994; 14:897-913. [PubMed: 8301368] 
Fawley JA, Peters JH, Andresen MC. GABAB-mediated inhibition of multiple modes of glutamate release in the nucleus of the solitary tract. J Neurophysiol. 2011; 106:1833-1840. [PubMed: 21734101]

Fuertes G, Laorden ML, Milanes MV. Noradrenergic and dopaminergic activity in the hypothalamic paraventricular nucleus after naloxone-induced morphine withdrawal. Neuroendocrinology. 2000a; 71:60-67. [PubMed: 10644900]

Fuertes G, Milanes MV, Rodriguez-Gago M, Marin MT, Laorden ML. Changes in hypothalamic paraventricular nucleus catecholaminergic activity after acute and chronic morphine administration. European journal of pharmacology. 2000b; 388:49-56. [PubMed: 10657546]

Giraudo SQ, Billington CJ, Levine AS. Effects of the opioid antagonist naltrexone on feeding induced by DAMGO in the central nucleus of the amygdala and in the paraventricular nucleus in the rat. Brain research. 1998; 782:18-23. [PubMed: 9519245]

Glass MJ, Briggs JE, Billington CJ, Kotz CM, Levine AS. Opioid receptor blockade in rat nucleus tractus solitarius alters amygdala dynorphin gene expression. Am J Physiol Regul Integr Comp Physiol. 2002; 283:R161-R167. [PubMed: 12069941]

Glatzer NR, Smith BN. Modulation of synaptic transmission in the rat nucleus of the solitary tract by endomorphin-1. J Neurophysiol. 2005; 93:2530-2540. [PubMed: 15615836]

Gordon FJ. Opioids and central baroreflex control: a site of action in the nucleus tractus solitarius. Peptides. 1990; 11:305-309. [PubMed: 2162532]

Hadjimarkou MM, Abbadie C, Kasselman LJ, Pan YX, Pasternak GW, Bodnar RJ. Changes in mouse mu opioid receptor Exon 7/8-like immunoreactivity following food restriction and food deprivation in rats. Synapse. 2009; 63:585-597. [PubMed: 19301417]

Hamra M, McNeil RS, Runciman M, Kunze DL. Opioid modulation of calcium current in cultured sensory neurons: mu-modulation of baroreceptor input. Am J Physiol. 1999; 277:H705-H713. [PubMed: 10444497]

Hassen AH, Feuerstein G. mu-opioid receptors in NTS elicit presor responses via sympathetic pathways. Am J Physiol. 1987; 252:H156-H162. [PubMed: 3028161]

Heinke B, Gingl E, Sandkühler J. Multiple targets of $\mu$-opioid receptor-mediated presynaptic inhibition

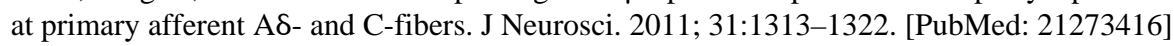

Itoh $\mathrm{H}$, Bunag RD. Age-related reduction of reflex bradycardia in conscious rats by catecholaminergic nucleus tractus solitarius lesions. Mechanisms of ageing and development. 1993; 67:47-63. [PubMed: 8469033]

Jia HG, Rao ZR, Shi JW. Evidence of gamma-aminobutyric acidergic control over the catecholaminergic projection from the medulla oblongata to the central nucleus of the amygdala. $\mathrm{J}$ Comp Neurol. 1997; 381:262-281. [PubMed: 9133568]

Kim EM, Quinn JG, Spanswick D, O'Hare E. Feeding association between the nucleus of the solitary tract and the ventral tegmental area. Appetite. 2009; 53:457-460. [PubMed: 19748538]

Kogan JH, Nestler EJ, Aghajanian GK. Elevated basal firing rates and enhanced responses to 8-BrcAMP in locus coeruleus neurons in brain slices from opiate-dependent rats. Eur J Pharmacol. 1992; 211:47-53. [PubMed: 1618268]

Kotz CM, Billington CJ, Levine AS. Opioids in the nucleus of the solitary tract are involved in feeding in the rat. Am J Physiol. 1997; 272:R1028-R1032. [PubMed: 9139997]

Kotz CM, Glass MJ, Levine AS, Billington CJ. Regional effect of naltrexone in the nucleus of the solitary tract in blockade of NPY-induced feeding. Am J Physiol Regul Integr Comp Physiol. 2000; 278:R499-R503. [PubMed: 10666153]

Kubo T, Goshima Y, Hata H, Misu Y. Evidence that endogenous catecholamines are involved in alpha 2-adrenoceptor-mediated modulation of the aortic baroreceptor reflex in the nucleus tractus solitarii of the rat. Brain research. 1990; 526:313-317. [PubMed: 2175243]

Lane-Ladd SB, Pineda J, Boundy VA, Pfeuffer T, Krupinski J, Aghajanian GK, Nestler EJ. CREB (cAMP response element-binding protein) in the locus coeruleus: biochemical, physiological, and behavioral evidence for a role in opiate dependence. J Neurosci. 1997; 17:7890-7901. [PubMed: 9315909]

Laorden ML, Fuertes G, Gonzalez-Cuello A, Milanes MV. Changes in catecholaminergic pathways innervating paraventricular nucleus and pituitary-adrenal axis response during morphine 
dependence: implication of alpha(1)- and alpha(2)-adrenoceptors. J Pharmacol Exp Ther. 2000; 293:578-584. [PubMed: 10773031]

Laorden ML, Nunez C, Almela P, Milanes MV. Morphine withdrawal-induced c-fos expression in the hypothalamic paraventricular nucleus is dependent on the activation of catecholaminergic neurones. J Neurochem. 2002; 83:132-140. [PubMed: 12358736]

Lee MC, Yasuda R, Ehlers MD. Metaplasticity at single glutamatergic synapses. Neuron. 66:859-870. [PubMed: 20620872]

Leibowitz SF, Sladek C, Spencer L, Tempel D. Neuropeptide Y, epinephrine and norepinephrine in the paraventricular nucleus: stimulation of feeding and the release of corticosterone, vasopressin and glucose. Brain research bulletin. 1988; 21:905-912. [PubMed: 3224284]

Manzoni OJ, Williams JT. Presynaptic regulation of glutamate release in the ventral tegmental area during morphine withdrawal. J Neurosci. 1999; 19:6629-6636. [PubMed: 10414991]

Martin-Schild S, Gerall AA, Kastin AJ, Zadina JE. Differential distribution of endomorphin 1- and endomorphin 2-like immunoreactivities in the CNS of the rodent. J Comp Neurol. 1999; 405:450 471. [PubMed: 10098939]

Navarro-Zaragoza J, Nunez C, Laorden ML, Milanes MV. Effects of corticotropin-releasing factor receptor-1 antagonists on the brain stress system responses to morphine withdrawal. Molecular pharmacology. 2010; 77:864-873. [PubMed: 20159948]

Navarro-Zaragoza J, Nunez C, Ruiz-Medina J, Laorden ML, Valverde O, Milanes MV. CRF mediates the increased noradrenergic activity in the hypothalamic paraventricular nucleus and the negative state of morphine withdrawal in rats. British journal of pharmacology. 2011; 162:851-862. [PubMed: 20973778]

Nomora S, Ding YQ, Kaneko T, Li JL, Mizuno N. Localization of mu-opioid receptor-like immunoreactivity in the central components of the vagus nerve: a light and electron microscope study in the rat. Neuroscience. 1996; 73(1):277-286. [PubMed: 8783249]

Nunez C, Castells MT, Laorden ML, Milanes MV. Regulation of extracellular signal-regulated kinases (ERKs) by naloxone-induced morphine withdrawal in the brain stress system. NaunynSchmiedeberg's archives of pharmacology. 2008; 378:407-420.

Nunez C, Martin F, Foldes A, Luisa Laorden M, Kovacs KJ, Victoria Milanes M. Induction of FosB/ DeltaFosB in the brain stress system-related structures during morphine dependence and withdrawal. J Neurochem. 2010; 114:475-487. [PubMed: 20438612]

Ohi Y, Kato F, Haji A. Codeine presynaptically inhibits the glutamatergic synaptic transmission in the nucleus tractus solitarius of the guinea pig. Neuroscience. 2007; 146:1425-1433. [PubMed: 17412514]

Olson VG, Heusner CL, Bland RJ, During MJ, Weinshenker D, Palmiter RD. Role of noradrenergic signaling by the nucleus tractus solitarius in mediating opiate reward. Science. 2006; 311:10171020. [PubMed: 16484499]

Palkovits M, Eskay RL. Distribution and possible origin of beta-endorphin and ACTH in discrete brainstem nuclei of rats. Neuropeptides. 1987; 9:123-137. [PubMed: 3033542]

Peters JH, McDougall SJ, Kellett DO, Jordan D, Llewellyn-Smith IJ, Andresen MC. Oxytocin enhances cranial visceral afferent synaptic transmission to the solitary tract nucleus. J Neurosci. 2008; 28:11731-11740. [PubMed: 18987209]

Petrov T, Krukoff TL, Jhamandas JH. Branching projections of catecholaminergic brainstem neurons to the paraventricular hypothalamic nucleus and the central nucleus of the amygdala in the rat. Brain Res. 1993; 609:81-92. [PubMed: 8099526]

Pickel VM, Chan J, Milner TA. Ultrastructural basis for interactions between central opioids and catecholamines. II. Nuclei of the solitary tracts. J Neurosci. 1989; 9:2519-2535. [PubMed: 2568412]

Pierce TL, Wessendorf MW. Immunocytochemical mapping of endomorphin-2- immunoreactivity in rat brain. J Chem Neuroanat. 2000; 18:181-207. [PubMed: 10781736]

Poole SL, Deuchars J, Lewis DI, Deuchars SA. Subdivision-specific responses of neurons in the nucleus of the tractus solitarius to activation of mu-opioid receptors in the rat. J Neurophysiol. 2007; 98:3060-3071. [PubMed: 17898143] 
Reyes BA, Van Bockstaele EJ. Divergent projections of catecholaminergic neurons in the nucleus of the solitary tract to limbic forebrain and medullary autonomic brain regions. Brain Res. 2006; 1117:69-79. [PubMed: 16962080]

Rhim H, Glaum SR, Miller RJ. Selective opioid agonists modulate afferent transmission in the rat nucleus tractus solitarius. J Pharmacol Exp Ther. 1993; 264:795-800. [PubMed: 8094753]

Riche D, De Pommery J, Menetrey D. Neuropeptides and catecholamines in efferent projections of the nuclei of the solitary tract in the rat. J Comp Neurol. 1990; 293:399-424. [PubMed: 1969868]

Rinaman L. Hindbrain noradrenergic A2 neurons: diverse roles in autonomic, endocrine, cognitive, and behavioral functions. Am J Physiol Regul Integr Comp Physiol. 2011; 300:R222-R235. [PubMed: 20962208]

Rogers RC, Travagli RA, Hermann GE. Noradrenergic neurons in the rat solitary nucleus participate in the esophageal-gastric relaxation reflex. Am J Physiol Regul Integr Comp Physiol. 2003; 285:R479-R489. [PubMed: 12714355]

Rukhadze I, Kubin L. Differential pontomedullary catecholaminergic projections to hypoglossal motor nucleus and viscerosensory nucleus of the solitary tract. J Chem Neuroanat. 2007; 33:23-33. [PubMed: 17134870]

Rusin KI, Moises HC. Mu-opioid and GABA(B) receptors modulate different types of Ca2+ currents in rat nodose ganglion neurons. Neuroscience. 1998; 85:939-956. [PubMed: 9639286]

Saper CB. The central autonomic nervous system: conscious visceral perception and autonomic pattern generation. Annu Rev Neurosci. 2002; 25:433-469. [PubMed: 12052916]

Sawchenko PE, Pfeiffer SW. Ultrastructural localization of neuropeptide Y and galanin immunoreactivity in the paraventricular nucleus of the hypothalamus in the rat. Brain Res. 1988; 474:231-245. [PubMed: 2463058]

Sawchenko PE, Swanson LW. Central noradrenergic pathways for the integration of hypothalamic neuroendocrine and autonomic responses. Science. 1981; 214:685-687. [PubMed: 7292008]

Simon OR, Basuray BN, West WL, Copeland R. Interaction between the baroreflex and anterior hypothalamic stimulation. Demonstration of a noradrenergic involvement. Neuropharmacology. 1985; 24:665-675. [PubMed: 4022277]

Smith RJ, Aston-Jones G. Noradrenergic transmission in the extended amygdala: role in increased drug-seeking and relapse during protracted drug abstinence. Brain structure \& function. 2008; 213:43-61. [PubMed: 18651175]

Sutton MA, Ito HT, Cressy P, Kempf C, Woo JC, Schuman EM. Miniature neurotransmission stabilizes synaptic function via tonic suppression of local dendritic protein synthesis. Cell. 2006; 125:785-799. [PubMed: 16713568]

Suzuki T, Takayama K, Miura M. Distribution and projection of the medullary cardiovascular control neurons containing glutamate, glutamic acid decarboxylase, tyrosine hydroxylase and phenylethanolamine N-methyltransferase in rats. Neurosci Res. 1997; 27:9-19. [PubMed: 9089694]

Travagli RA, Hermann GE, Browning KN, Rogers RC. Brainstem circuits regulating gastric function. Annu Rev Physiol. 2006; 68:279-305. [PubMed: 16460274]

Ueta Y, Kannan H, Higuchi T, Negoro H, Yamaguchi K, Yamashita H. Activation of gastric afferents increases noradrenaline release in the paraventricular nucleus and plasma oxytocin level. J Auton Nerv Syst. 2000; 78:69-76. [PubMed: 10789684]

Van Bockstaele EJ, Menko AS, Drolet G. Neuroadaptive responses in brainstem noradrenergic nuclei following chronic morphine exposure. Mol Neurobiol. 2001; 23:155-171. [PubMed: 11817217]

Van Giersbergen PL, Roording P, de Lang H, de Jong W. Participation of opiate receptors located in the nucleus tractus solitarii in the hypotension induced by alpha-methyldopa. Brain Res. 1989; 498:154-158. [PubMed: 2551454]

Vaughan CW, Ingram SL, Connor MA, Christie MJ. How opioids inhibit GABA-mediated neurotransmission. Nature. 1997; 390:611-614. [PubMed: 9403690]

Velley L, Milner TA, Chan J, Morrison SF, Pickel VM. Relationship of Met-enkephalin-like immunoreactivity to vagal afferents and motor dendrites in the nucleus of the solitary tract: a light and electron microscopic dual labeling study. Brain Res. 1991; 550:298-312. [PubMed: 1715806] 
Wang X, Cen X, Lu L. Noradrenaline in the bed nucleus of the stria terminalis is critical for stressinduced reactivation of morphine-conditioned place preference in rats. European journal of pharmacology. 2001; 432:153-161. [PubMed: 11740951]

Wang ZJ, Rao ZR, Shi JW. Tyrosine hydroxylase-, neurotensin-, or cholecystokinin-containing neurons in the nucleus tractus solitarii send projection fibers to the nucleus accumbens in the rat. Brain Res. 1992; 578:347-350. [PubMed: 1380865]

Xu T, Wang T, Han J. Involvement of opioid receptors in nucleus tractus solitarii in modulating endotoxic hypotension in rats. Neurosci Lett. 1992; 146:72-74. [PubMed: 1335562]

Yang Y, Atasoy D, Su HH, Sternson SM. Hunger states switch a flip-flop memory circuit via a synaptic AMPK-dependent positive feedback loop. Cell. 2011; 146:992-1003. [PubMed: 21925320]

Zhu W, Pan ZZ. Mu-opioid-mediated inhibition of glutamate synaptic transmission in rat central amygdala neurons. Neuroscience. 2005; 133:97-103. [PubMed: 15893634] 


\section{Highlights}

Mu opioids inhibit visceral afferent activation of NTS catecholamine neurons.

Inhibition is through a presynaptic mechanism to decrease glutamate release.

Opioids reduce both afferent evoked action potentials and basal firing rate.

The effect is greater in catecholamine vs. non-catecholamine neurons in the NTS. 

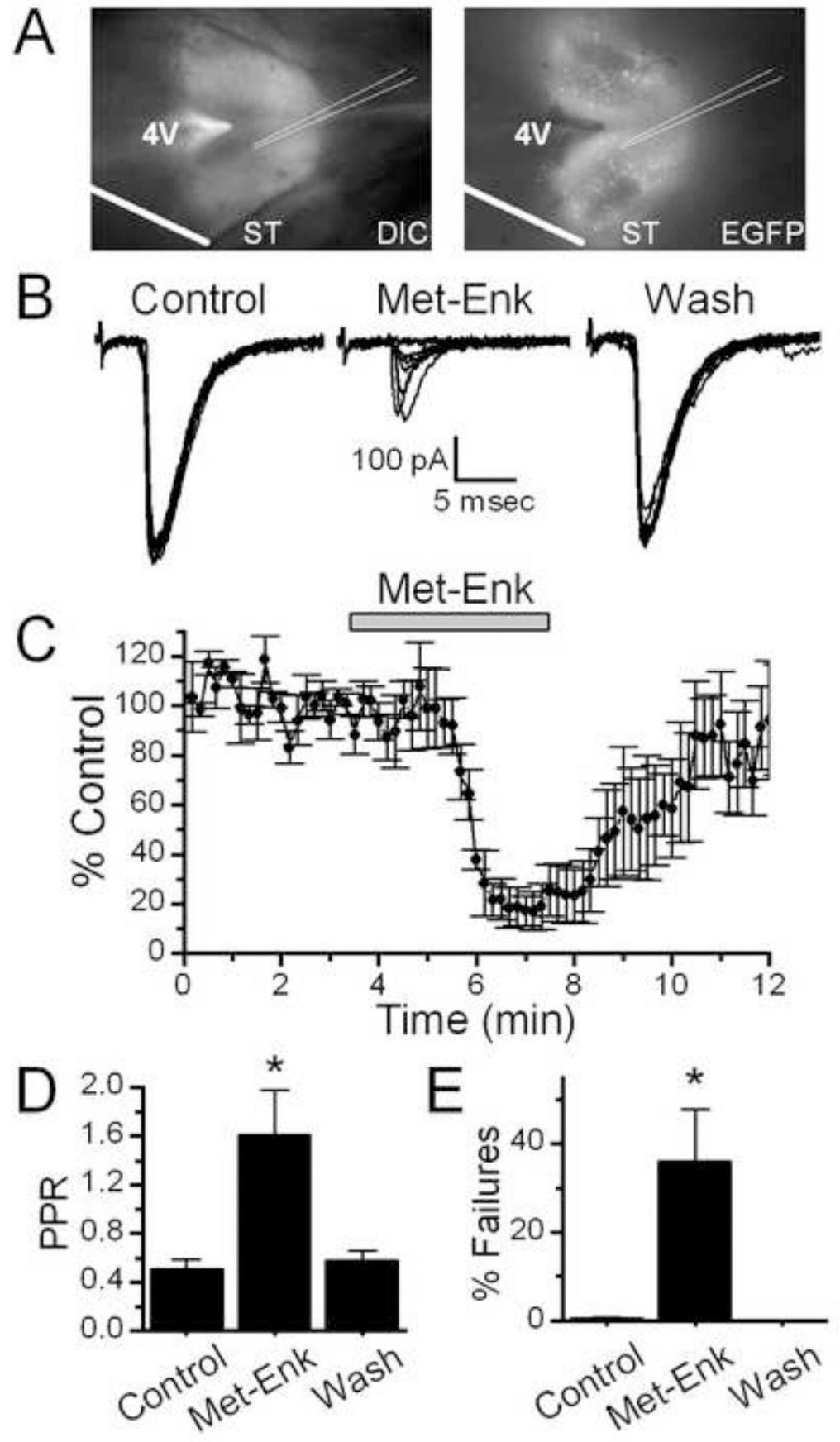

Figure 1.

Met-enkepahlin (Met-Enk) inhibits solitary tract evoked TH-EGFP synaptic responses in horizontal brainstem slices. A. Visualization of the NTS horizontal brain-slice preparation from a TH-EGFP mouse using DIC and florescence. Scale bar $=0.5$ mM. B. Representative traces ST-stimulated EPSCs (ST-EPSCs), with 10 overlapping sweeps shown. Met-Enk significantly inhibited the amplitude of the ST-EPSCs. This effect was reversed following a 5-10 minute wash. C. A graph showing the effect of Met-Enk on ST-EPSC amplitude over time. Met-Enk rapidly decreased the ST-EPSC amplitude in a manner that was quickly reversed following wash (n=5). D. A graph showing Met-Enk increases the paired pulse ration (PPR, EPSC2/EPSC1) 
$(\mathrm{n}=7)$. E. A graph showing Met-Enk increases the failure rate $(\%$ failures $=($ number of failures $/$ total stimulations $) * 100)$ in TH-EGFP neurons $(n=7) .{ }^{*} p<0.05$ (One way ANOVA). 

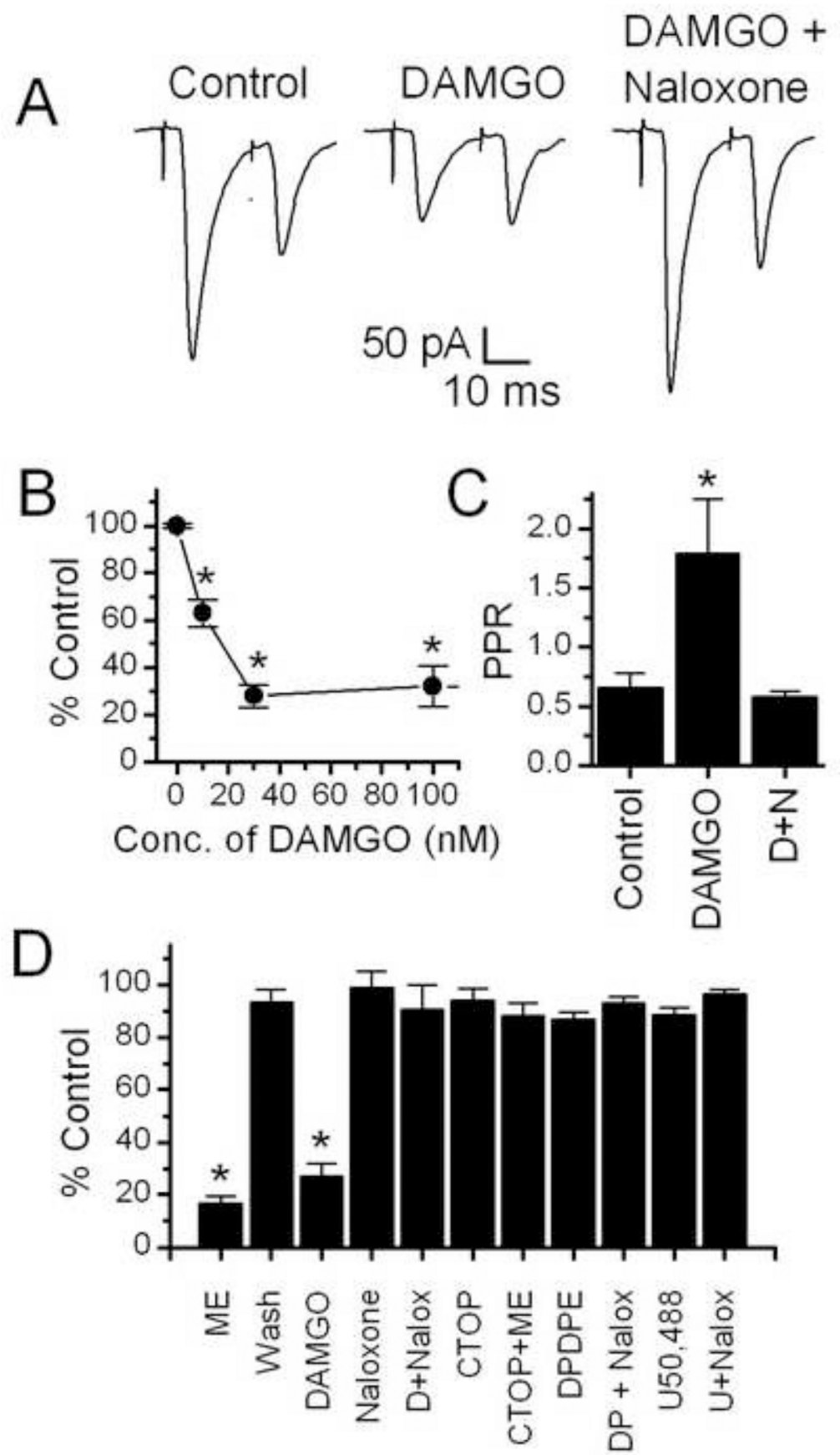

Figure 2.

The mu opioid specific agonist DAMGO significantly inhibited ST-EPSCs. A. Representative traces of a pair of ST-EPSCs (an average of 10 sweeps is shown, stimulated $20 \mathrm{~ms}$ apart) showing inhibition by $10 \mathrm{nM}$ DAMGO and reversal by the opioid anatagonist naloxone (10 uM). B. Dose Response curve for DAMGO's inhibition of the ST-EPSCs. 10nM, 30nM and 100nM DAMGO all significantly inhibited the amplitude of the ST-EPSC ( $\mathrm{p}<0.001$, One way ANOVA). C. Bar graph showing the paired pulse ratio (PPR) under control conditions, in100nM DAMGO and in 100nM DAMGO + 10uM naloxone. The PPR was significantly increased by DAMGO, an effect reversed by naloxone ( $<<0.05$, One way ANOVA). D+N = DAMGO + Naloxone. D. Bar graph showing the average inhibition of the ST-EPSC by opioid agonists and blockade by opioid antagonists. Shown are 
Met-Enk (10uM), DAMGO (100nM, D), the delta receptor selective agonist DPDPE (1 uM, DP), the kappa selective agonist U50,488 (1 uM, U) and blockade of the effect by the non-specific opioid antagonist, naloxone (10uM) and the mu opioid receptor specific antagonist CTOP $(1 \mathrm{uM})$; Both Met-Enk and DAMGO significantly inhibited the control EPSC amplitude by an average of $824 \%$ and $736 \%$ respectively ( $p<0.005$, Paired Student $t$ test), all other treatments did not have significant effects compared to control. 

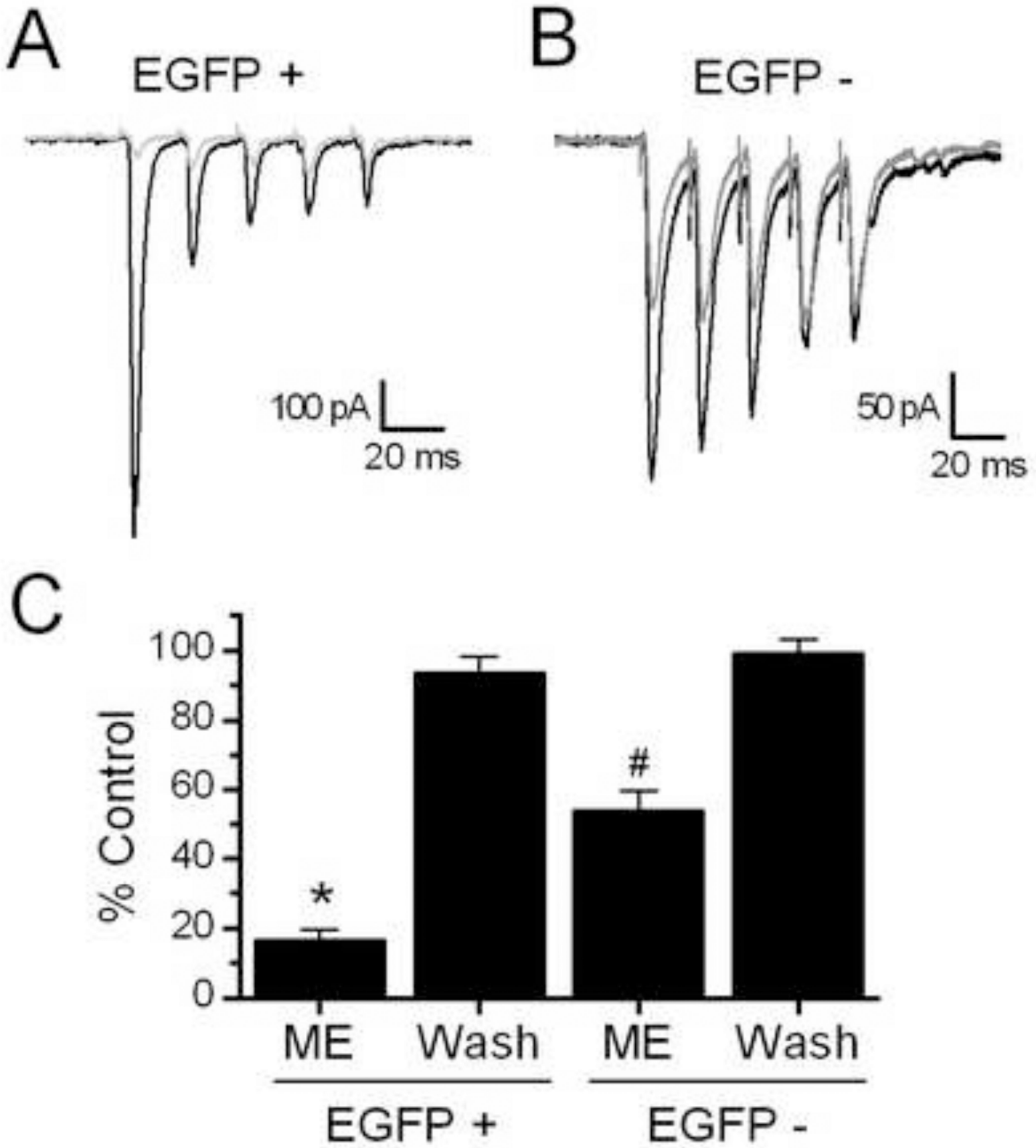

Figure 3.

Opioids induce a greater inhibition of the ST-EPSCs in TH-EGFP positive vs. EGFP negative neurons. A. Representative traces showing the effect of Met-Enk in EGFP positive (+) and negative (-) NTS neurons. Both neurons were second order NTS neurons, with monosynaptic connections with incoming afferents using established criteria (Doyle \& Andresen, 2001). The THEGFP neuron had a latency of $3.2 \mathrm{~ms}$ and jitter (STDEV of latency) of $77.6 \mathrm{usec}$, with no failures in control (ACSF). The EGFP negative neuron had a latency of $3.0 \mathrm{~ms}$ and jitter of $110 \mathrm{usec}$, again with no failures in control. B. Graph showing the average effect of Met-Enk and wash in TH-EGFP positive and negative NTS neurons. The effect of Met-Enk was significantly greater in 
TH-EGFP + compared to EGFP - neurons $\left(^{*}=\mathrm{p}<0.005\right.$ compared to control in EGFP + neurons and from Met-Enk effect in EGFP - neuron, Student's t test; \# = p $<0.005$ from control in EGFP - neurons and from Met-Enk effect in EGFP + neurons) 

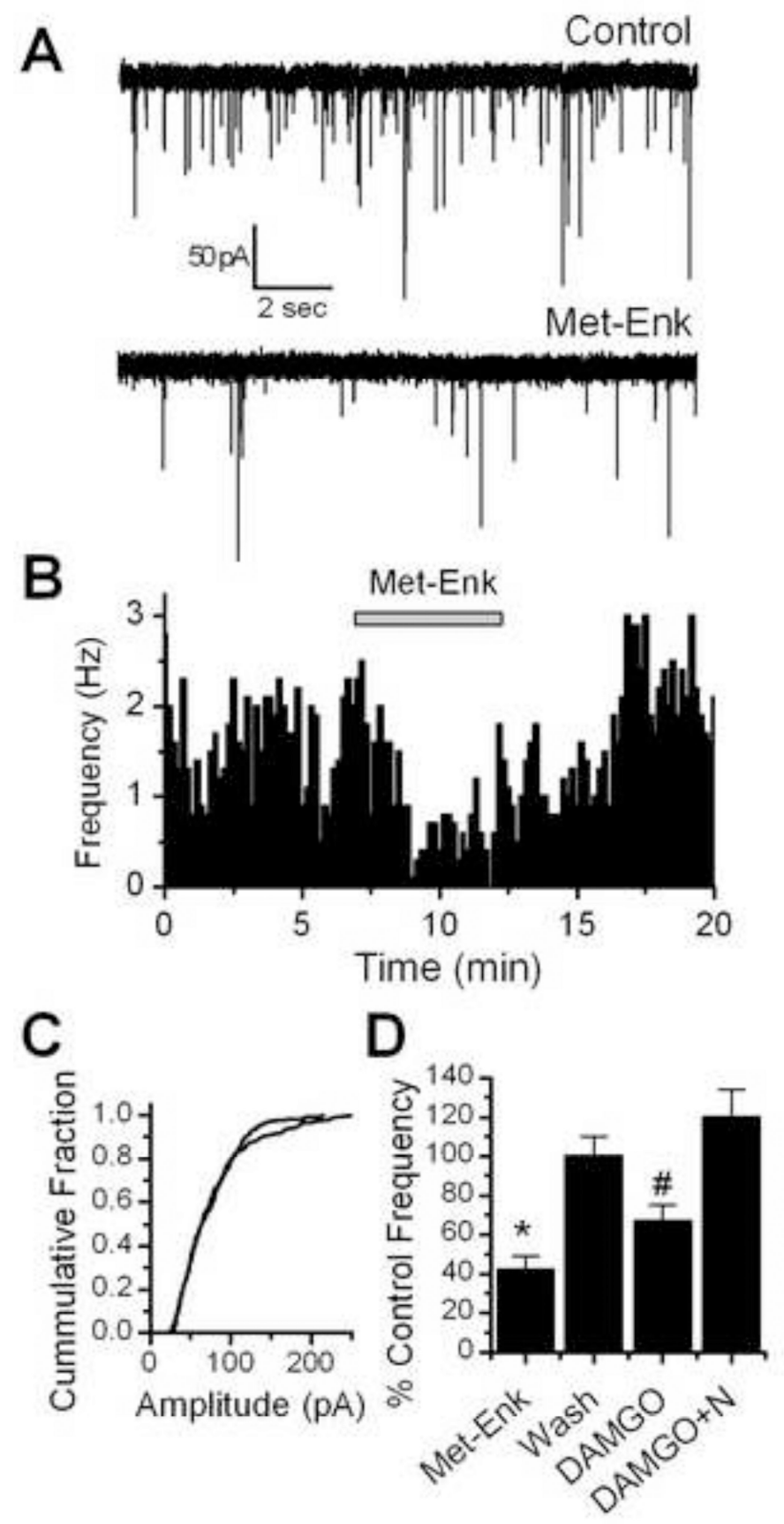

Figure 4.

Met-Enk decreased the frequency of miniature EPSCs (mEPSCs) in NTS TH-EGFP neurons. A. Representative traces of mEPSCs in control conditions and in the presence of Met-Enk $(10 \mu \mathrm{M})$. B. Graph showing the effect of Met-Enk $(10 \mu \mathrm{M})$ over time. Met-Enk significantly decreased the rate of mEPSCs ( $p<0.05$, KS test) and this effect was reversed by a $5-10$ minute wash. C. Graph showing the cumulative distribution of mEPSC amplitudes in a representative neuron in control and Met-Enk treated conditions. No significant change was seen in mEPSC amplitude ( $p>0.05, \mathrm{KS}$ test). D. Graph showing the average inhibition of mEPSC frequency by Met-Enk $(10 \mu \mathrm{M})$ and DAMGO (300nM). The effect of Met-Enk was reversed by a 10 
minute wash and the effects of DAMGO were reversed by the opioid receptor antagonist naloxone $(10 \mu \mathrm{M}) .{ }^{*} \mathrm{p}<0.05$ (One way ANOVA). 

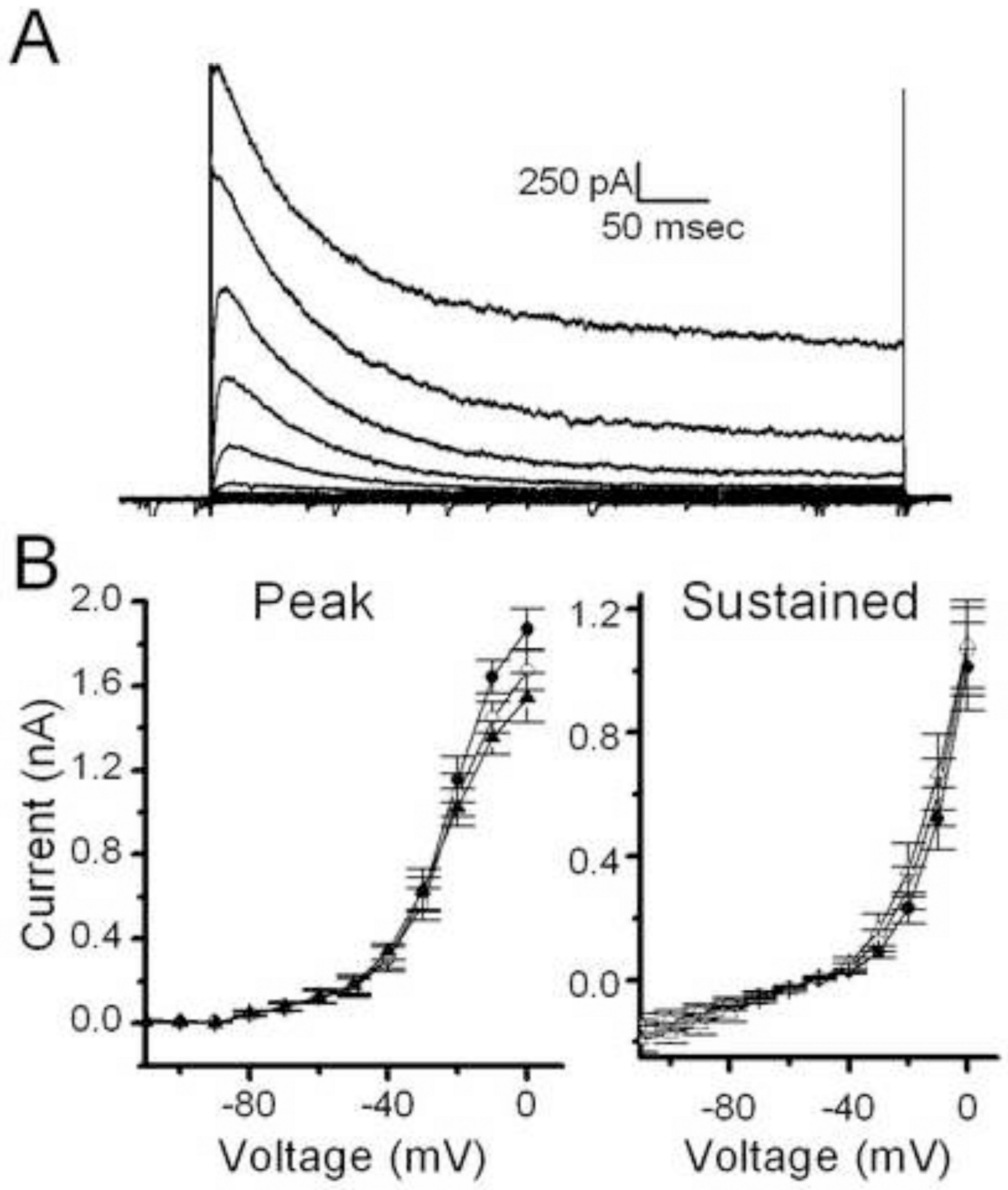

Figure 5.

Met-Enk has no effect on current-voltage relationships in TH-EGFP neurons. A. A representative trace from a current clamp experiment showing typical currents elicited in TH-EGFP neurons by increasing voltage steps following a brief step to $-120 \mathrm{mV}$ to remove inactivation. B. Average current-voltage relationship of peak current (left) and sustained current (right) in control, Met-Enk and following a 10 minute wash $(\mathrm{n}=6)$. 

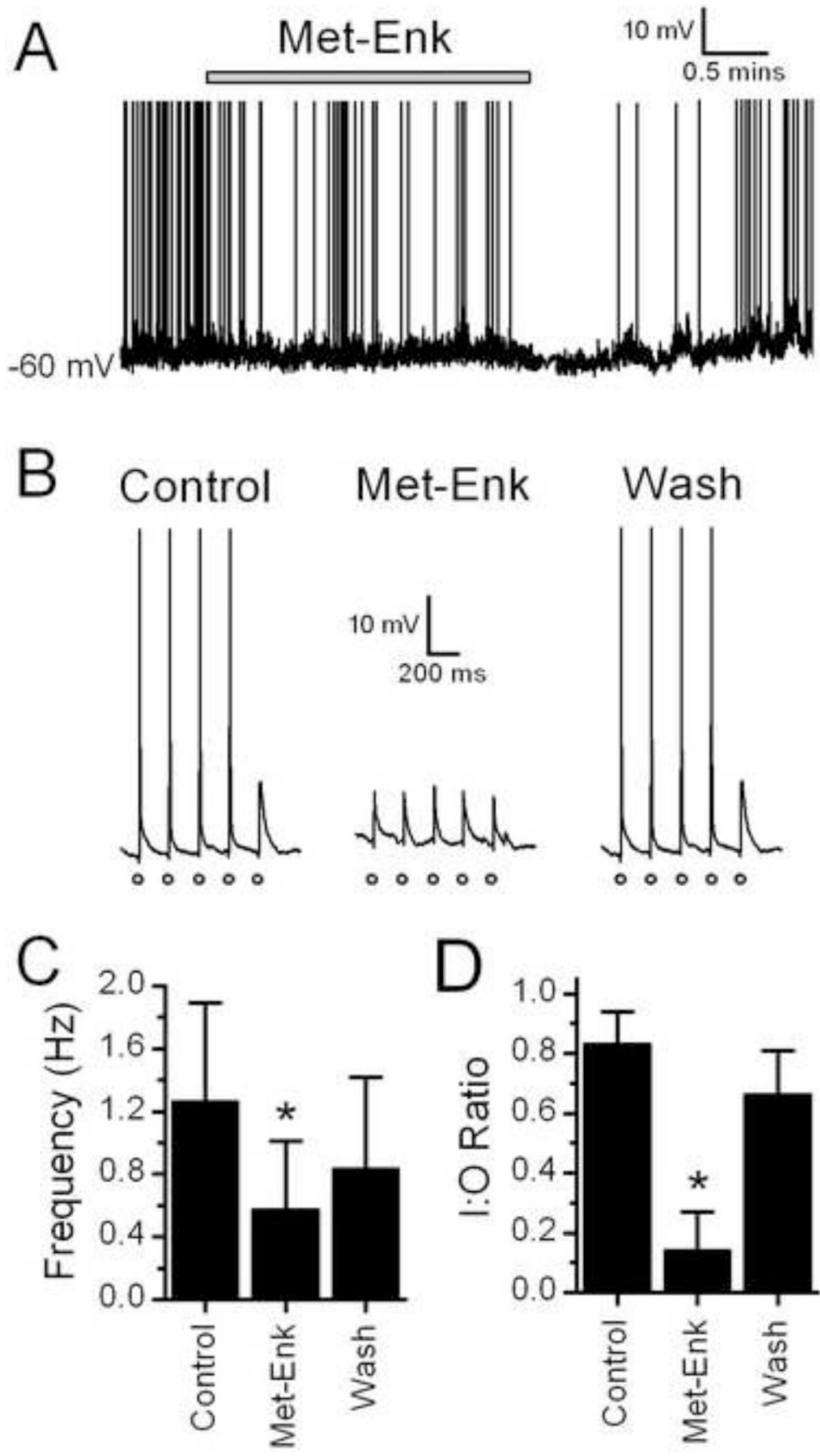

Figure 6.

Met-Enk decreases afferent evoked action potentials in TH-EGFP neurons. A. A representative trace from a current clamp experiment showing control (basal) AP frequency and the effect of a bath application of Met-Enk and wash in ACSF in a THEGFP neuron. Met-Enk significantly reduced the AP frequency in this example ( $<<0.05, \mathrm{KS}$ test), an effect reversed by wash. B. Representative trace showing ST-stimulated APs in a TH-EGFP neuron. A train of 5 stimulations was given to the ST at $0.2 \mathrm{~Hz}$ (each stimulation is represented by o). Under control conditions the majority of trains resulted in an AP. In the presence of Met-

Enk stimulation of the ST failed to evoke an AP. This inhibition was partially reversed following wash. C. Average AP 
frequency in control (ACSF), 10uM Met-Enk and wash (ACSF). D. Average I:O ratio in control, Met-Enk and Wash. APs are truncated at $0 \mathrm{mV} . *=p<0.005$ (One way ANOVA). 